\title{
Involvement of Serotonin in the Excitation of Phrenic Motoneurons Evoked by Stimulation of the Raphe Obscurus
}

\author{
Joseph R. Holtman, Jr., ${ }^{1}$ Thomas E. Dick, and Albert J. Berger \\ Department of Physiology and Biophysics, University of Washington School of Medicine, \\ Seattle, Washington 98195
}

Short-latency averaged responses in the $\mathrm{C5}$ phrenic nerves to electrical stimulation (2.5-80 $\mu \mathrm{A} ; 5-80 \mathrm{~Hz} ; 150 \mu$ sec pulse duration) of raphe pallidus (RP) and raphe obscurus (RO) were investigated in anesthetized, paralyzed, and artificially ventilated cats. The responses to stimulation of $\mathrm{RO}$ were excitatory, whereas a mixture of inhibitory and excitatory responses of lesser magnitude were observed after stimulating in RP. The maximal response was obtained from the ventral part of RO and consisted of early and delayed excitatory responses that were of equal magnitude in both left and right $\mathrm{C5}$ phrenic nerve roots. The mean latency for the early response was $2.5 \pm 0.1 \mathrm{msec}$ and for the delayed response was $7.0 \pm 0.2 \mathrm{msec}$. Both responses were elicited during inspiratory phase stimulation, but only the delayed response was present during expiratory phase stimulation. The stimulus threshold of the early response was 5 $\mu \mathrm{A}$; the delayed response was elicited at currents as small as $2.5 \mu \mathrm{A}$. Early and delayed responses were affected in different ways by increasing stimulus current and by increasing stimulus frequency. Intravenous administration of serotonin receptor antagonists methysergide (0.1-0.7 mg/kg), metergoline (33-244 $\mu \mathrm{g} / \mathrm{kg}$ ), and cinanserin $(1.5-9.0 \mathrm{mg} / \mathrm{kg})$ caused significant doserelated reductions in the magnitude of the delayed response, but did not significantly affect the early response. These data suggest that the early and delayed excitatory responses are mediated by different neuronal pathways. The early response does not involve serotonin release, while the later response is mediated at least in part by activation of a serotonergic pathway. The early excitatory response may be mediated by descending bulbospinal inspiratory axons that decussate in the midline before proceeding to the spinal cord to activate phrenic motoneurons. However, the delayed excitatory response probably occurs as a result of activation of serotonergic cell bodies in RO. These cell bodies likely project to medullary respiratory nuclei, which then project to the spinal cord to excite phrenic motoneurons. These findings are important in that they identify a specific

Received June 24, 1985; revised Sept. 13, 1985; accepted Sept. 18, 1985

This study was supported by USPHS Javits Neuroscience Investigator Award NS 14857 to A.I.B., and USPHS Grant RR00374 for the LM$^{2}$ laboratory computer. J.R.H. and T.E.D. are Parker B. Francis Fellows of the Puritan-Bennett Foundation. The authors gratefully acknowledge the assistance of William Satterthwaite in the performance of these experiments, the late Eileen LaBossiere for histology, Patrick Roberts for photography, and Hanna Atkins for preparing the illustrations and the manuscript. Also, we thank Sandoz for the methysergide, Farmitalia for the metergoline, Squibb for the cinanserin, and Glaxo for the Althesin used in this study. A preliminary report of these results was presented at the Federation of American Societies for Experimental Biology, Anaheim, CA, April 1985.

Correspondence should be addressed to J. R. Holtman, Jr., Ph.D., Department of Pharmacology, University of Kentucky College of Medicine, Lexington, KY 40536.

' This work was done while J.R.H. was on leave from the Department of Pharmacology, Georgetown University Schools of Medicine and Dentistry, Washington, DC 20007

Copyright (C) 1986.Society for Neuroscience $0270-6474 / 86 / 041185-09 \$ 02.00 / 0$ respiratory motor response mediated by a specific neurotransmitter and a brain stem nucleus.

Evidence from recent anatomical and physiological studics indicates that the caudal raphe nuclei, consisting of the raphe obscurus (RO), raphe pallidus (RP), and raphe magnus (RM), may be involved in neural control of respiration. Retrograde and anterograde tracing techniques have revealed that the caudal raphe nuclei project to nuclei known to be involved in respiratory control. These nuclei include the phrenic motor nucleus (PMN) in the spinal cord and the nuclei of the tractus solitarius, which includes the dorsal respiratory group in the medulla. Holtman et al. (1984a) showed that RO, RP, and RM project into the area of the PMN in the cervical spinal cord. In addition, the RM was also shown to project to the nuclei of the tractus solitarius (Basbaum et al., 1978).

Using neurochemical and immunohistochemical techniques, the neurotransmitter serotonin, which is localized primarily in cell bodies of the raphe nuclei (Dahlström and Fuxe, 1964; Poitras and Parent, 1978; Wiklund et al., 1981), has been shown to be present in several nuclei involved with respiratory control. Oliveras et al. (1977) found a high serotonin content in micropunches from the ventral horn of the cervical spinal cord at $\mathrm{C} 5$ and $\mathrm{C6}$, the location of the PMN column. Furthermore, serotonin-containing varicosities, which are thought to represent nerve terminals, have been found surrounding phrenic motoneurons (Holtman et al., 1984b). Serotonin-containing varicosities have also been identified in the area of the nuclei of tractus solitarius (Maley and Elde, 1982), as well as in nucleus ambiguus (Steinbusch, 1981), the latter constituting a portion of the medullary ventral respiratory group. Significant amounts of serotonin have been found in micropunches from the area of the nuclei of tractus solitarius and also in nucleus ambiguus (Palkovits et al., 1974).

Stimulation of the caudal raphe nuclei produces changes in respiratory activity. As early as 1939 , Pitts and colleagues reported changes in respiratory activity in the spontaneously breathing cat induced by electrical stimulation of RO, RP, and RM. Stimulation within RO and RM resulted in mixed effects, observed as either a tonic inspiration or tonic expiration, whereas stimulation within the RP resulted in tonic inspiration. Sessle and colleagues (1981) reported that stimulation of RM inhibits inspiration as brief stimuli resulted in periods of apnea. Changes in overall phrenic nerve activity have also been observed during electrical stimulation of the caudal raphe nuclei. Phrenic nerve activity was increased by stimulation of RP and decreased by stimulation of RM (Dretchen et al., 1983). Holtman and coworkers (1986) showed that stimulation of RO causes an increase in phrenic nerve activity. Changes in phrenic nerve activity were also seen after microinjection of L-glutamate into the RO. This finding indicates that activation of RO cell bodies and not axons of passage (Goodchild et al., 1982) is responsible 
for the increase in the phrenic nerve activity. Lalley (1985) recorded intracellularly from phrenic motoneurons and found that stimulation of RO causes inhibition, but that stimulation of the RP causes excitation of phrenic motoneuron spontaneous activity.

In summary, data from prior studies indicate that serotonergic neurons of caudal raphe nuclei may be involved in respiratory control. However, as only single sites of stimulation within each raphe nucleus typically were studied and the role of serotonin in mediating changes in respiratory activity was not addressed, we felt that a more complete evaluation needed to be done. In the present study, we have systematically examined the effects of stimulation of the caudal raphe nuclei on short-latency phrenic nerve responses and determined whether the neurotransmitter serotonin mediates the observed responses. We have focused on the RO and RP and characterized the short-latency phrenic nerve responses elicited by electrical stimulation throughout the entire rostrocaudal and dorsoventral aspects of these nuclei. Furthermore, the effects of several serotonin antagonists (methysergide, metergoline, and cinanserin) have been evaluated for their abilities to block the evoked phrenic nerve responses to stimulation of RO.

\section{Materials and Methods}

\section{General surgical procedures}

Twenty-four cats of either sex, ranging in weight from 1.8 to $3.5 \mathrm{~kg}$, were anesthetized initially with Althesin $(20 \mathrm{mg} / \mathrm{kg}$, i.m., Glaxo Vet, England), followed by chloralose-urethane ( 30 and $150 \mathrm{mg} / \mathrm{kg}$, i.v.). Supplemental doses of chloralose-urethane were administered to maintain anesthesia. A femoral artery and vein were cannulated for measurement of blood pressure and administration of drugs, respectively. Blood pressure was continuously recorded on a Gould/Brush polygraph. The trachea was also cannulated and end-tidal $\mathrm{CO}_{2}$ measured (Beckman LB-2) and maintained at $5-6 \%$ by adding $\mathrm{CO}_{2}$ to the inspired hyperoxic gas mixture. The animals were paralyzed with gallamine $(5 \mathrm{mg} / \mathrm{kg} / \mathrm{hr}$ ) and artificially ventilated. Rectal temperature was monitored and maintained at $38-39^{\circ} \mathrm{C}$ with infrared lamps.

\section{Phrenic nerve recording}

The procedure for recording phrenic nerve activity has been described elsewhere (Berger, 1977). A dorsal midline incision was made initially, extending from the occipital ridge to the $\mathrm{T} 2$ vertebra. The right and left C5 phrenic nerves were dissected free from the surrounding connective tissue. The nerves were cut at their distal ends and desheathed. After the cats were mounted in a Kopf stereotaxic apparatus and spinal unit, each nerve was placed on a platinum bipolar recording electrode and immersed in warm mineral oil. Neural signals were amplified (Grass $\mathrm{P} 15)$, filtered (1 $\mathrm{Hz}-10 \mathrm{kHz})$, and displayed on an oscilloscope; the oscilloscope signal was sent to a signal-averaging computer (Princeton Applied Research) for analysis. The neural signals were also full-waverectified, integrated using a "leaky integrator" circuit, and the integrated output continuously recorded on the polygraph to monitor inspiratory output.

\section{Electrical stimulation}

The overlying muscles of the head and neck were dissected, and a limited occipital craniotomy was performed to expose the caudal cerebellum and medulla. The dura was cut and retracted, and the caudal half of the cerebellum was removed by aspiration, thereby exposing the dorsal surface of the medulla. A stimulating electrode (stainless steel, monopolar, 200-500 k $\Omega$ ) was positioncd perpendicular to the medullary surface and then visually aligned with the midline using the obex as a reference point. A stimulator (Grass S88) connected to a constant-current isolation unit (Grass PSIU6) delivered square-wave pulses at points throughout the RO and RP. Parameters for electrical stimulation were in the range of $2.5-80 \mu \mathrm{A}, 5-80 \mathrm{~Hz}$, with stimulus pulses of $150 \mu \mathrm{sec}$ duration. Generally, stimuli were applied throughout the inspiratory phase as well as the expiratory phase of the respiratory cycle. At the end of each experiment, stimulation sites were marked by passing a current of $100 \mu \mathrm{A}$ for $5 \mathrm{sec}$. The brain stem was then removed and placed in $10 \%$ formalin in $0.9 \% \mathrm{NaCl}$. Fifty-micron sections were cut either in a sagittal or a transverse plane. Sections were stained with cresyl violet and Luxol fast blue. Lesion sites were identified using a microprojector (Bausch \& Lomb).

\section{Data analysis}

Short-latency responses in the phrenic nerves to electrical stimulation within RO and RP were analyzed using signal-averaging techniques. The trigger to the averager was generated by the stimulator. The parameters for averaging were 200 sweeps, $1024 \mathrm{bins}$ with $40 \mu \mathrm{sec} / \mathrm{bin}$. We simultaneously averaged both right and left phrenic nerve responses on line. After acquisition of each pair of averages, the averaging computer memory was sent to an $\mathbf{L M}^{2}$ laboratory computer for storage on floppy disk for subsequent plotting and analysis. The evoked responses were quantified by determining the areas under each response (peak) using a digitizing tablet (Numonics $\mathrm{Co}$.). In order to compare data between cats, the areas were converted to the percentage of maximal response for the current and frequency response curves, and to the percentage of control (vehicle only) for dose-response curves in the pharmacological experiments.

\section{Pharmacological studies}

Three serotonin antagonists (Fuller, 1980) were evaluated for their effects on the evoked phrenic nerve averaged responses to stimulation within RO: methysergide (Sandoz, East Hanover, NJ), metergoline (Farmitalia, Milan, Italy), and cinanserin (E. J. Squibb, Princeton, NJ). These compounds have been found to be selective serotonin antagonists (McCall, 1984; Proudfit and Anderson, 1974). Methysergide and cinanserin were dissolved in $0.9 \% \mathrm{NaCl}$; metergoline was dissolved in $95 \%$ ethanol.

Cumulative dose-response curves were generated by intravenous administration of each drug. Initially, the effect of vehicle control on evoked responses in phrenic nerve was evaluated. Neither $0.9 \% \mathrm{NaCl}$ nor $95 \%$ ethanol caused significant changes in evoked responses. After administration of the respective vehicle control, successive doses of each drug were administered at 5-15 min intervals. The effects of the drug on evoked responses in phrenic nerve were determined just prior to administration of the next dose of drug. The level of phrenic nerve activity was observed to decrease in some cats after the higher doses of serotonin antagonists. When this decrease occurred, inspired $\mathrm{CO}_{2}$ was increased to maintain phrenic nerve activity at pre-drug injection control level. All drug responses were converted to percentage of control, the latter being the evoked response obtained after administration of the respective vehicle in which each drug was dissolved.

\section{Statistical analysis}

Current and frequency response curves, as well as the dose-response curves, were evaluated by regression analysis (Snedecor and Cochran, 1967). The Student's $t$ test for paired data was used for all other comparisons. The level of statistical significance for each test was $p<0.05$. In all cases, values are reported as means \pm SEM.

\section{Results}

\section{Anatomical mapping of the averaged responses}

elicited in the phrenic nerve by electrical

stimulation of raphe obscurus and raphe pallidus

We began our study by determining what types of averaged phrenic nerve responses could be evoked by electrical stimulation during inspiration within the RO and RP. Responses to stimulation $(50 \mu \mathrm{A}, 20 \mathrm{~Hz}, 150 \mu \mathrm{sec}$ pulse duration) were mapped along the entire rostrocaudal and dorsoventral extents of the RO and RP as defined by Taber and colleagues (1960). Stimulations were made at $5,4,3,2$, and $1 \mathrm{~mm}$ rostral to the obex, at the obex, and at $1 \mathrm{~mm}$ caudal to the obex. In each track, the stimulations were performed in $500 \mu \mathrm{m}$ increments from the dorsal surface of the medulla. This procedure was performed in six cats, and a representative map is presented on a midsagittal section of the medulla in Figure 1. The extents of RO and RP are represented in this figure by dashed lines; $\mathrm{RO}$ can be seen to begin just caudal to the obex and to extend to about $5 \mathrm{~mm}$ rostral to the obex. The RP begins near the obex and extends rostrally for 5 to $6 \mathrm{~mm}$. Rostrally, the RO and RP can be seen 


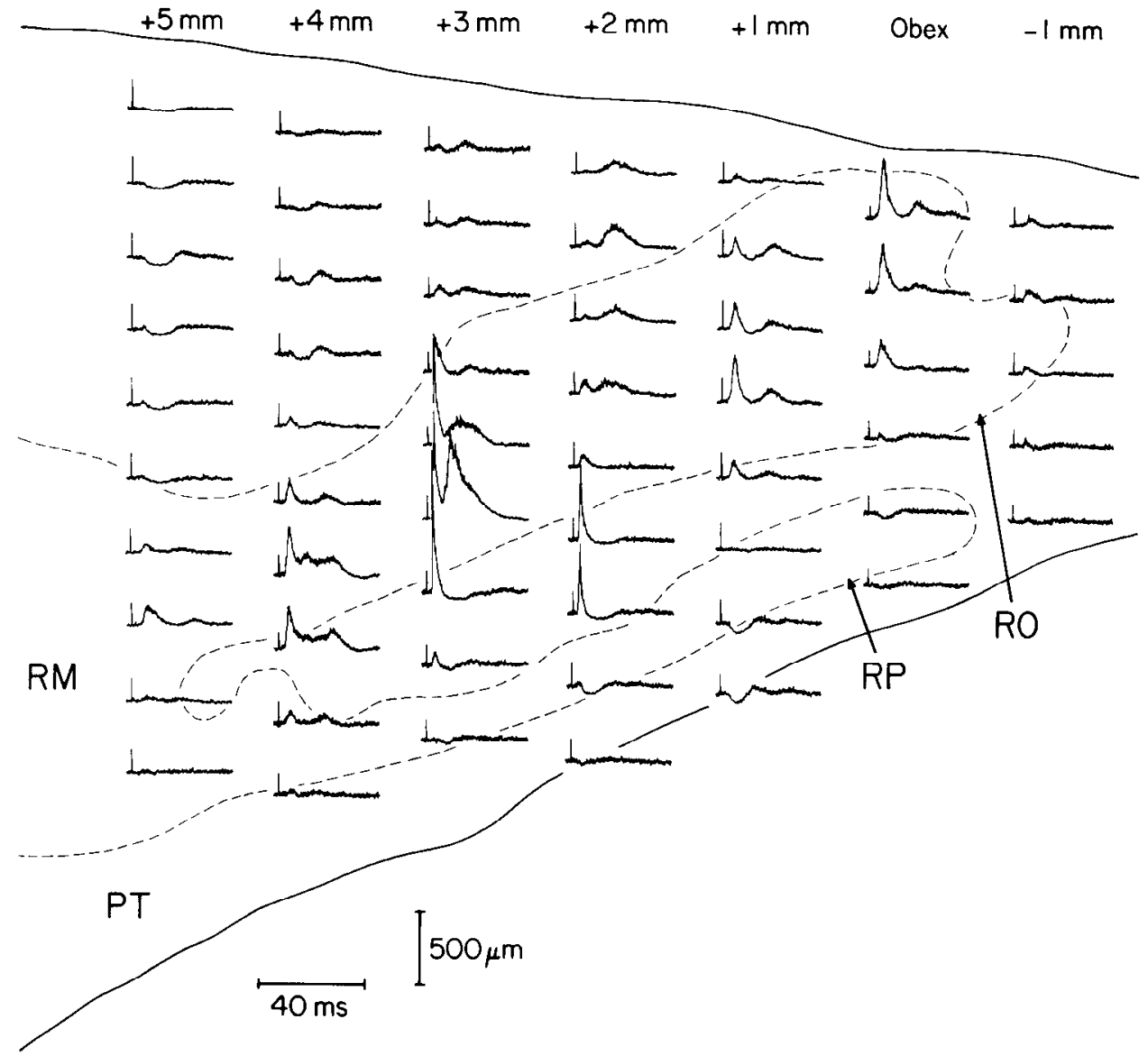

Figure 1. Representative map in the midsagittal plane of the averaged C5 phrenic nerve responses elicited by electrical stimulation of the raphe obscurus and pallidus. Stimulations were made during inspiration at -1 to +5 $\mathrm{mm}$ from obex and at $500 \mu \mathrm{m}$ increments from the dorsal surface of the medulla. Stimulus parameters: $50 \mu \mathrm{A}$, $20 \mathrm{~Hz}$, and $150 \mu$ sec. $P T$, Pyramidal tract; $R M$, raphe magnus; $R O$, raphe obscurus; $R P$, raphe pallidus.

to merge with the RM. Focusing first on RP, one can see that the averaged responses elicited in the phrenic nerves were mixed. Electrical stimulation produced excitation, inhibition, or no response. An example of an excitatory response is seen at $+4 \mathrm{~mm}$ and $4500 \mu \mathrm{m}$. The inhibitory responses were more numerous and can be seen at $+2 \mathrm{~mm}$ and $4000 \mu \mathrm{m},+1 \mathrm{~mm}$ and 3500 $\mu \mathrm{m}$, or obex and $2500 \mu \mathrm{m}$. In some instances, the electrical stimulations produced essentially no response, as can be seen at $+5 \mathrm{~mm}$ and $5000 \mu \mathrm{m},+3 \mathrm{~mm}$ and $4500 \mu \mathrm{m}$, or $+1 \mathrm{~mm}$ and $3000 \mu \mathrm{m}$.

The type of response elicited in the phrenic nerves by electrical stimulation within $\mathrm{RO}$ was clearer. The predominant responses were excitatory. Examples can be observed in all of the tracks at various depths along the entire rostrocaudal extent of the RO. Although excitatory responses were elicited in the phrenic nerves by stimulating at several sites within $\mathrm{RO}$, the maximal excitatory response in the six cats tested consistently occurred at +2 or $+3 \mathrm{~mm}$ rostral to the obex and at 2500 or $3000 \mu \mathrm{m}$ deep from the dorsal surface of the medulla. Figure 1 shows the excitation, consisting of an early and a delayed excitatory response at $+3 \mathrm{~mm}$ and $3000 \mu \mathrm{m}$.

We focused our attention on this site within RO to characterize more completely the nature of the early and delayed excitatory responsc. To determine the mediolateral extent of the excitatory response, electrical stimulation $(50 \mu \mathrm{A}, 20 \mathrm{~Hz}, 150$ $\mu \mathrm{sec}$ pulse duration) was performed within the midline and at 1 and $2 \mathrm{~mm}$ on either side of the midline. Stimulations were again performed at $500 \mu \mathrm{m}$ intervals from the surface of the medulla. These mediolateral stimulation experiments were done in four cats, and a representative map of the results from one animal is presented on a cross section of the medulla in Figure 2 . In this plane, the maximal excitatory response occurred in the midline within RO at $2500 \mu \mathrm{m}$ (Fig. 2). In the four cats tested, the depth of the maximal delayed excitatory response occurred at 2500 or $3000 \mu \mathrm{m}$. The site of the maximal excitatory response in each animal was always dorsal to the inferior olive. The distance rostral from the obex, where the maximal excitatory response occurred, ranged from 2.0-2.2 mm. Evidence of excitation was also present at 1 and $2 \mathrm{~mm}$ lateral to the midline. At $1 \mathrm{~mm}$ lateral, the response was present at $3000 \mu \mathrm{m}$, whereas at $2 \mathrm{~mm}$ lateral, the response was present at $3500 \mu \mathrm{m}$. Although present in these lateral tracks, the excitatory response was centered in the midline and was much diminished at $2 \mathrm{~mm}$ lateral to the midline.

\section{Electrophysiological characterizations of the averaged excitatory response elicited in the phrenic nerve by electrical stimulation of the raphe obscurus}

Following anatomical characterization of the averaged excitatory response elicited by electrical stimulation of the $\mathrm{RO}$, the averaged excitatory response was characterized electrophysiologically. First, we investigated whether early and delayed excitatory responses occurred in both right and left phrenic nerves, and whether the responses could be elicited when stimulation was applied during expiration. This was done in four cats and representative results from one animal are presented in Figure 3. This figure shows that early and delayed excitatory responses are clearly present in a single-sweep record as well as in the averaged record (cf. $A$ and $B$, Fig. 3). The latency, form, and magnitude of both early and delayed responses were similar in the left and right $\mathrm{C} 5$ phrenic nerves. Both excitatory responses were present when electrical stimulation was applied during inspiration; however, only the delayed response could be elicited in each of the phrenic nerves when stimulation was applied during expiration (Fig. 3).

Clear separation between the early and delayed excitatory 
Figure 2. Representative map in the transverse plane of the averaged C5 phrenic nerve responses elicited by electrical stimulation, both within and lateral to the raphe obscurus and pallidus. Stimulations were made during inspiration in the midline and at 1 and $2 \mathrm{~mm}$ on each side of the midline at $500 \mu \mathrm{m}$ increments from the dorsal surface of the medulla. Stimulus parameters: $50 \mu \mathrm{A}, 20 \mathrm{~Hz}$, and $150 \mu \mathrm{sec} . D M V$, Dorsal motor nucleus of the vagus; $P T$, pyramidal tract; $R O$, raphe obscurus; $R P$, raphe pallidus; $T S$, tractus solitarius; $X I I$, hypoglossal nucleus.

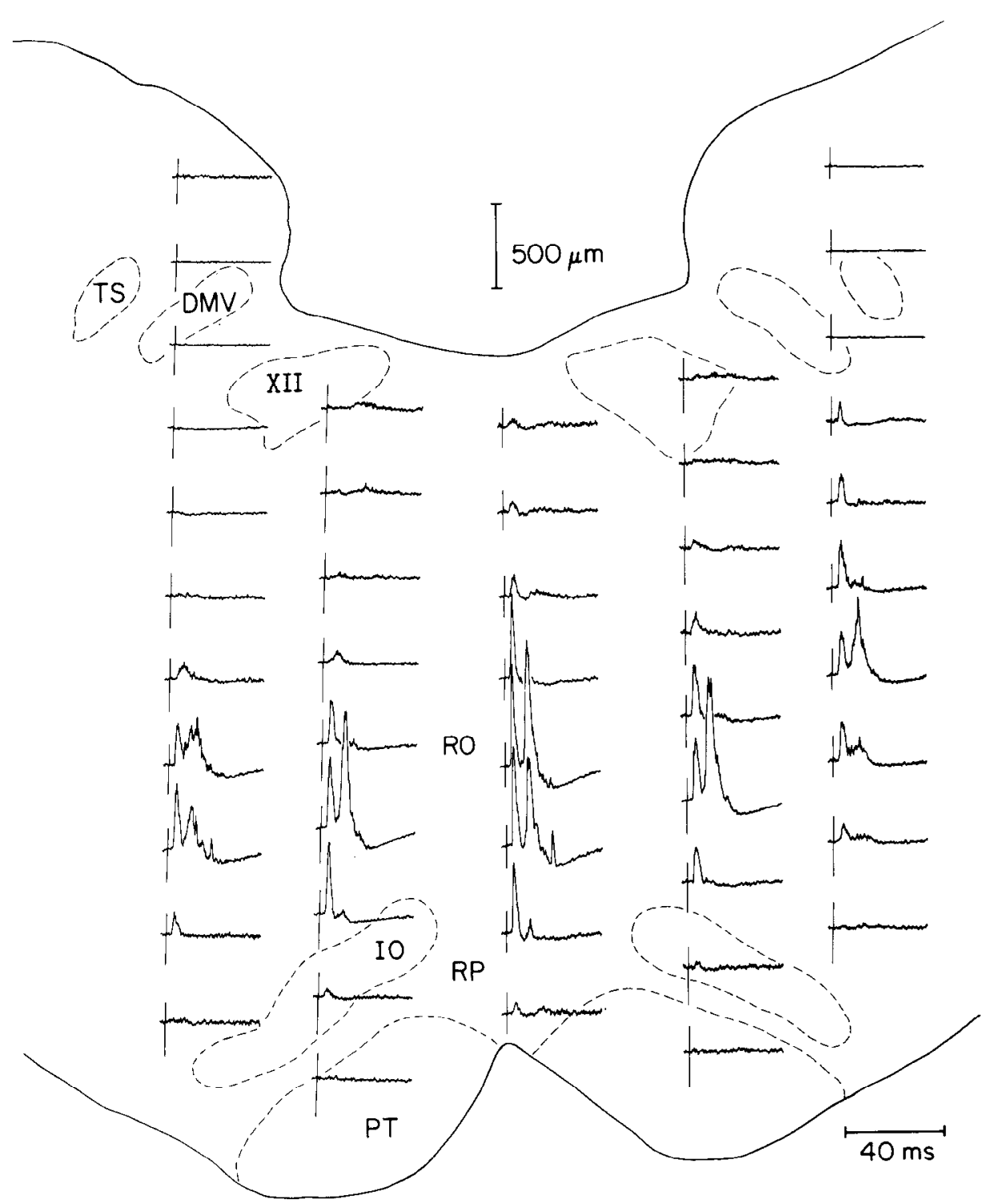

responses in the phrenic nerves allowed for calculations of onset and peak latency times. Results of these calculations in 19 cats are presented in Table 1. The average latency-to-onset was $2.5 \pm$ $0.1 \mathrm{msec}$ for the early response and $7.0 \pm 0.2 \mathrm{msec}$ for the dclayed response. The peak of the early response occurred about $1 \mathrm{msec}$ (latency-to-peak of $3.6 \pm 0.1 \mathrm{msec}$ ) after its onset; this brief time is indicative of the sharpness of this peak. The peak of the delayed response occurred about $3 \mathrm{msec}$ after its onset (a latency-to-peak of $10.2 \pm 0.2 \mathrm{msec}$ ); this longer time is indicative of the greater width of this peak compared with the earlier one.

The effect of altering stimulus intensity $(2.5-80 \mu \mathrm{A})$ and stimulus frequency $(5-80 \mathrm{~Hz})$ on the early and delayed excitatory responses was tested. These tests were performed on 10 and 9 cats, respectively, and the results are presented in Figures 4 and 5. Magnitudes of both the early and delayed responses increased with current intensity (Fig. 4). The threshold for the early response was approximately $5 \mu \mathrm{A}$, while the delayed response could be elicited at currents as small as $2.5 \mu \mathrm{A}$. The maximum for the early response occurred at $40-80 \mu \mathrm{A}$; the delayed response continued to increase for currents as high as $80 \mu \mathrm{A}$. Magnitudes of the early and delayed responses were also dependent on stimulus frequency, but neither response was linearly related to stimulus frequency. The early response was max- imal at $5-10 \mathrm{~Hz}$, reached a minimum at $40 \mathrm{~Hz}$, and then began to increase at $80 \mathrm{~Hz}$. The magnitude of the delayed response was linearly related to frequency up to $20 \mathrm{~Hz}$, but decreased at 40 and $80 \mathrm{~Hz}$.

\section{Pharmacological characterization of averaged responses elicited in phrenic nerve by electrical stimulation of raphe obscurus}

In order to determine if either or both components of the excitatory response elicited in the phrenic nerve by electrical stimulation of RO was mediated by serotonin, we first tried blocking the response with methysergide. Methysergide was administered intravenously in successive doses at $5 \mathrm{~min}$ intervals to five cats; representative results from one cat are presented in Figure 6. Successive doses of methysergide caused a dose-related reduction in the magnitude of the delayed response, which was essentially abolished after a dose of $0.7 \mathrm{mg} / \mathrm{kg}$. However, following this, a small-amplitude, delayed response could be evoked when stimulus intensity was increased to $100 \mu \mathrm{A}$. Methysergide had no significant effect on the magnitude of the early response. For all cats tested with methysergide, the cumulative dose-response curve is shown in Figure $7 A$. One can see that only the delayed excitatory response is significantly affected by the drug. The slope of the early excitatory response curve was not significantly 
INSPIRATION

Control

A.

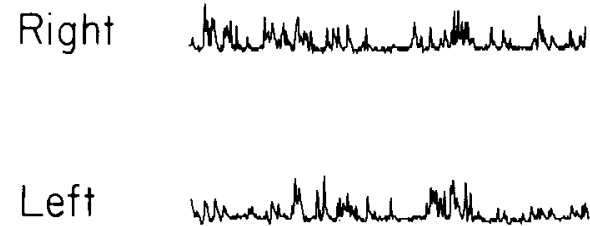

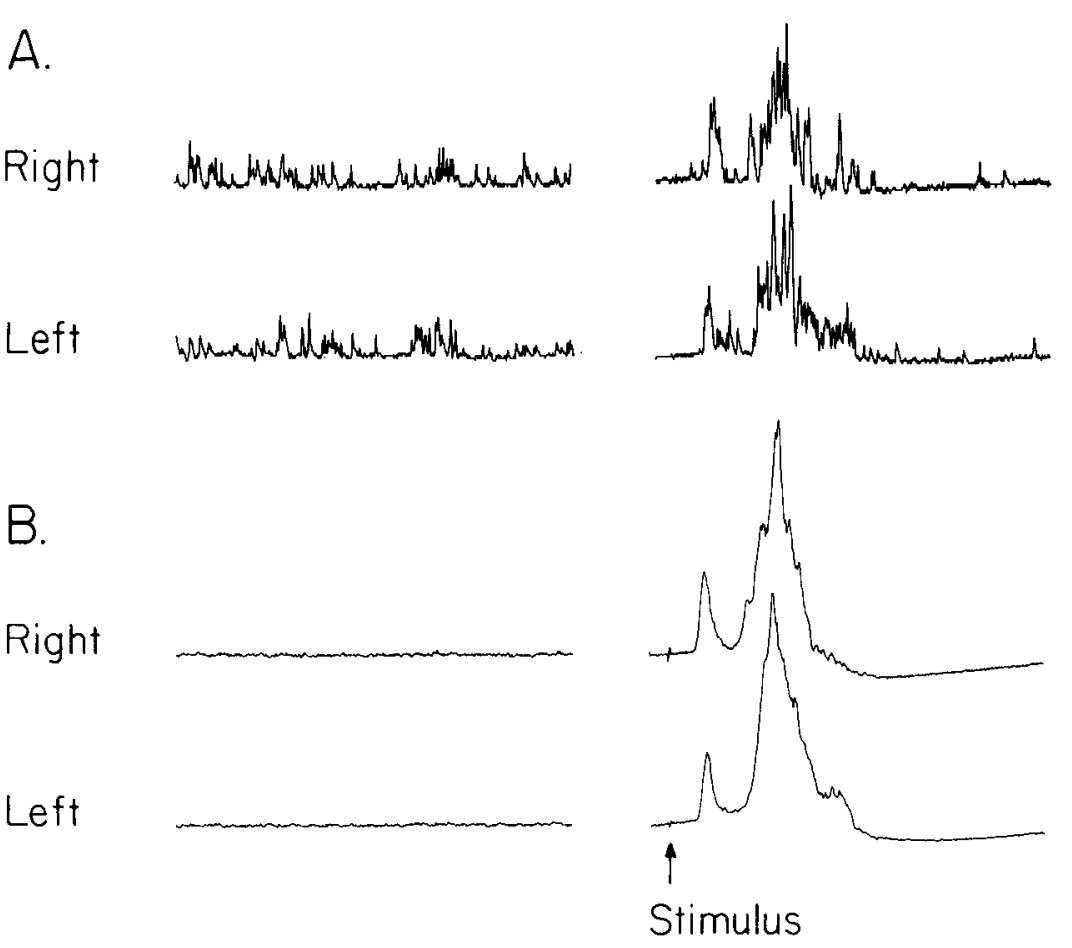

EXPIRATION

Stimulation
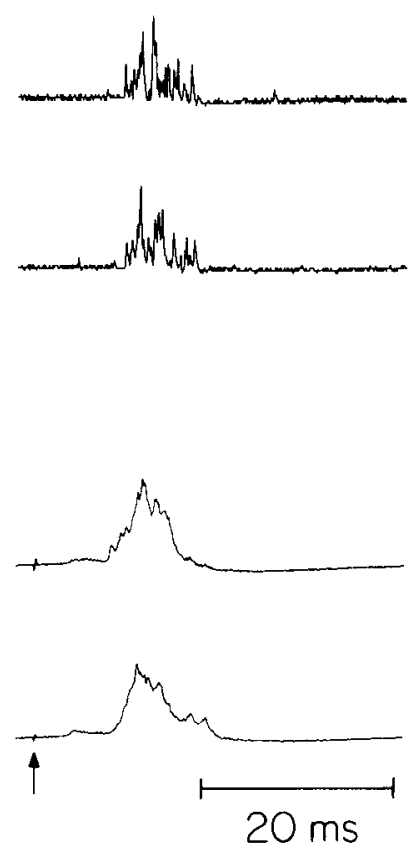

Figure 3. Representative responses in simultaneously recorded right and left $\mathrm{C} 5$ phrenic nerves elicited by electrical stimulation of the raphe obscurus during inspiration and expiration. $A$, Single sweep responses; $B$, averaged responses. Control records are without stimulation. Stimulus parameters $(A, B): 50 \mu \mathrm{A}, 20 \mathrm{~Hz}$, and $150 \mu \mathrm{sec}$.

different from zero. Two other serotonin receptor antagonists, metergoline and cinanserin, were also tested for their abilities to block the delayed excitatory response. Successive doses of metergoline were administered intravenously at 10 min intervals to five cats, and the results are shown in Figure $7 B$. Metergoline also caused a significant dose-related reduction in the magnitude of the delayed excitatory response. The slope of the early excitatory response did not differ significantly from zero, indicating that metergoline also had no dose-related effect on the early response. Successive doses of cinanserin were administered at $15 \mathrm{~min}$ intervals to four cats, and the results are shown in Figure $7 \mathrm{C}$. Cinanserin also caused a significant reduction (although much smaller) in the magnitude of the delayed response, but had no significant effect on the early response. Whereas methysergide and metergoline at high enough doses could abolish the delayed excitatory response evoked at $50 \mu \mathrm{A}$,

Table 1. Onset and peak latency times for the averaged C5 phrenic nerve responses elicited by electrical stimulation of the raphe obscurus

\begin{tabular}{llc} 
& $\begin{array}{l}\text { Latency-to-onset } \\
(\mathrm{msec})\end{array}$ & $\begin{array}{l}\text { Latency-to-peak } \\
(\mathrm{msec})\end{array}$ \\
\hline Early response & $2.5 \pm 0.1$ & $3.6 \pm 0.1$ \\
& $(1.9-2.8)$ & $(2.8-4.6)$ \\
Delayed response & $7.0 \pm 0.2$ & $10.2 \pm 0.2$ \\
& $(5.6-8.3)$ & $(9.0-11.6)$
\end{tabular}

Values are means \pm SEM; $n=19$. Values in parentheses are ranges. Stimulus parameters for evoking responses were $50 \mu \mathrm{A}, 20 \mathrm{~Hz}$, and $150 \mu \mathrm{sec}$. cinanserin only reduced the response to $85 \%$ of control. The maximal reduction occurred at the $6.0 \mathrm{mg} / \mathrm{kg}$ dose; larger doses of cinanserin did not produce any greater reductions in the magnitude of the delayed response. The reduction at $9.0 \mathrm{mg} / \mathrm{kg}$ was not significantly different from that at $6.0 \mathrm{mg} / \mathrm{kg}$. Doses larger than $9.0 \mathrm{mg} / \mathrm{kg}$ were not possible, as they produced cardiotoxicity characterized by severe hypotension and arrhythmias, often resulting in death of the animal.

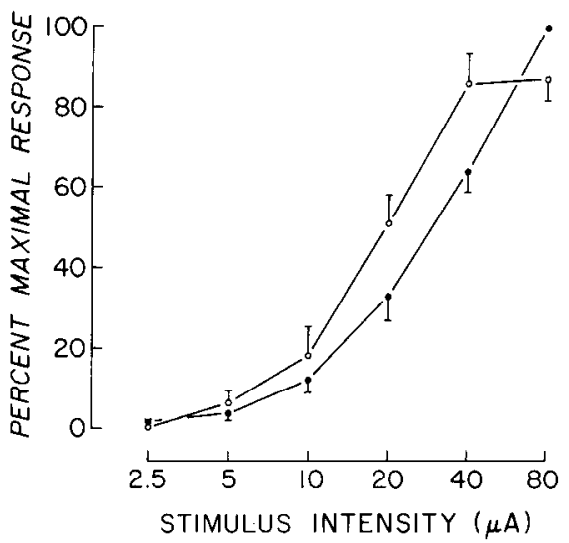

Figure 4. Averaged C5 phrenic nerve responses elicited by electrical stimulation of the raphe obscurus during inspiration as a function of stimulus intensity. Values are means $\pm \mathrm{SEM} ; n=10$ cats at each point. Stimulus parameters: $20 \mathrm{~Hz}, 150 \mu \mathrm{sec}$. Early response, open circles; delayed response, filled circles. 


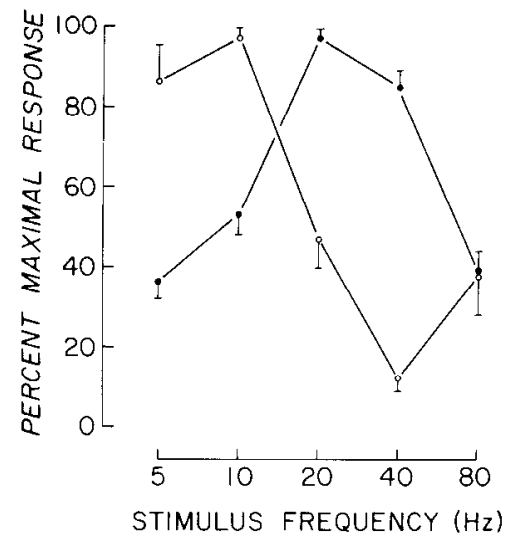

Figure 5. Averaged C5 phrenic nerve responses elicited by electrical stimulation of the raphe obscurus during inspiration as a function of stimulus frequency. Values are means $\pm \mathrm{SEM} ; n=$ nine cats at each point. Stimulus parameters: $50 \mu \mathrm{A}, 150 \mu \mathrm{sec}$. Early response, open circles; delayed response, filled circles.

\section{Discussion}

The results of the present study indicate that inspiratory phase stimulation of RO and RP produces short-latency responses in the phrenic nerves. The responses in the RO were excitatory, while a mixture of inhibitory and excitatory responses of smaller magnitude were observed in the RP. The maximal response obtained was from the ventral part of RO; it consisted of early and delayed excitatory responses that were of equal magnitude in both the left and right $\mathrm{C} 5$ phrenic nerve roots. This response appears to be similar to the one reported by Pitts (1943) with electrical stimulation in the midline.

Several findings indicate that the early and delayed responses are mediated, at least in part, by different neuronal pathways. Evidence for this includes (1) the different onset latencies of the responses; (2) different current and frequency response relationships; (3) presence of the delayed responsc, but not the carly response, during expiratory-phase stimulation; and (4) reduction in magnitude of the delayed but not the early response by serotonin receptor antagonists.

The early response probably results from stimulation of bulbospinal inspiratory axons that cross the midline in this part of the RO before proceeding to the spinal cord, where they monosynaptically excite phrenic motoneurons (Lipski et al., 1983). This conclusion is supported by both neurophysiological and neuroanatomical evidence. First, the mean latency-to-onset of $2.5 \pm 0.1 \mathrm{msec}$ and mean latency-to-peak of $3.6 \pm 0.1 \mathrm{msec}$ for this response are consistent with direct stimulation of inspiratory bulbospinal axons. Mean axonal conduction velocity of inspiratory bulbospinal axons is approximately $55 \mathrm{~m} / \mathrm{sec}$ (Dick and Berger, 1985). Mean axonal conduction velocity of phrenic motoneuronal axons is also approximately $55 \mathrm{~m} / \mathrm{sec}$ (Berger, 1979). These values lead to a calculated mean axonal conduction time of about $1.7 \mathrm{msec}$ for the $95 \mathrm{~mm}$ distance between the point of stimulation in the $\mathrm{RO}$ and the phrenic nerve recording site. If a utilization time of $0.25 \mathrm{msec}$ (see Dick and Berger, 1985) for generation of the descending volley, a chemical synaptic delay of $0.5 \mathrm{msec}$ (Eccles, 1968) and a delay of $0.3 \mathrm{msec}$ to initiate the phrenic motoneuron axonal spike from the start of the EPSP are included (see Berry and Pentreath, 1976), then the observed latency-to-onset and latency-to-peak of the early phrenic response are consistent with direct activation of inspiratory bulbospinal axons. Second, decussating axons from bulbospinal inspiratory neurons have been identified in the midline, where we stimulated and produced the early response in the phrenic nerves. Berger et al. (1984) made intracellular in-

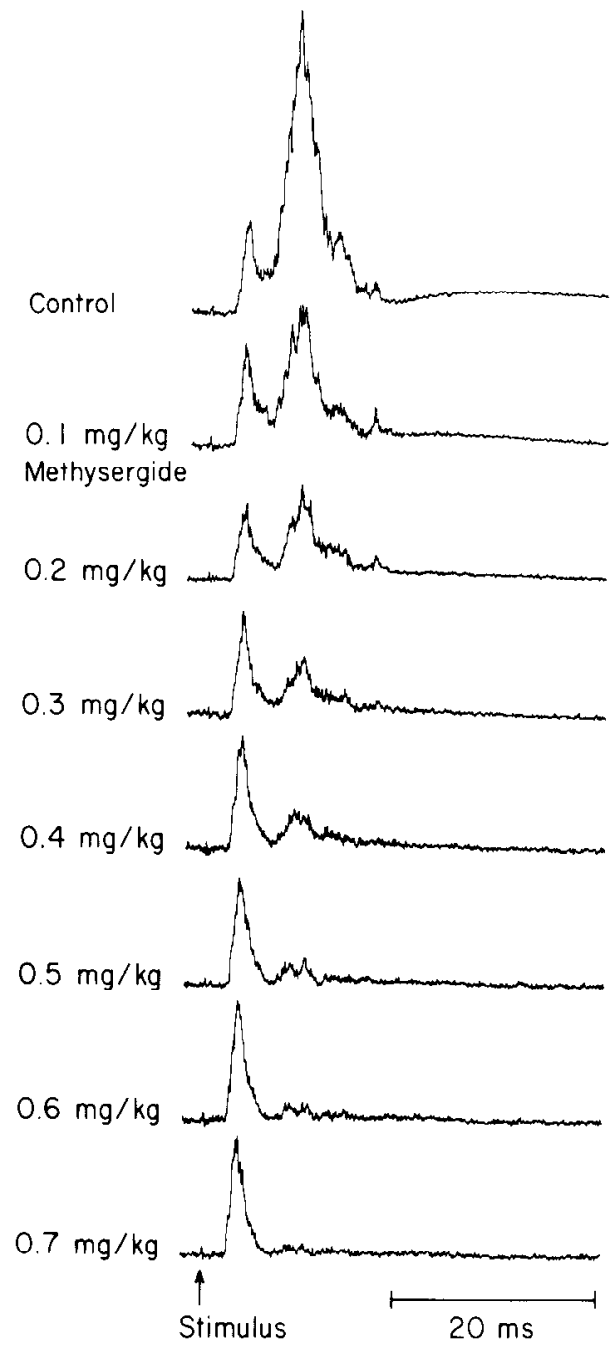

Figure 6. Representative cumulative dose-response of the effects of intravenous methysergide on averaged $\mathrm{C} 5$ phrenic nerve responses elicited by electrical stimulation of the raphe obscurus during inspiration. Stimulus parameters: $50 \mu \mathrm{A}, 20 \mathrm{~Hz}$, and $150 \mu \mathrm{sec}$.

jections of HRP into inspiratory neurons in ventrolateral nucleus tractus solitarius, the dorsal respiratory group. They found that axons of these inspiratory neurons coursed ventrally and then followed the midline before decussating (and likely projecting to the spinal cord). Merrill (1974) found that stimulation in the midline, just rostral to the obex, resulted in antidromic activation of inspiratory neurons. Furthermore, midsagittal lesions just rostral to the obex abolished inspiratory spinal motoneuronal activity (Bainton et al., 1978). The presence of an early response following stimulation lateral to the midline is also consistent with the intramedullary projection of inspiratory bulbospinal axons (Berger et al., 1984; Merrill, 1974). All of the above findings, taken together, support our conclusion that the early response in the phrenic nerve observed in the present study arises from electrical stimulation of descending inspiratory bulbospinal axons.

The delayed response in the phrenic nerves elicited by stimulation of $\mathrm{RO}$ is of greater interest. Whereas the early response is most likely caused by stimulation of axons of passage, the delayed response probably results from activation of cell bodies of RO. This conclusion is supported by previous findings of Holtman et al. (1986). These investigators used L-glutamate to activate cell bodies from a part of the RO similar to that examined in the present study. Microinjection of L-glutamate re- 

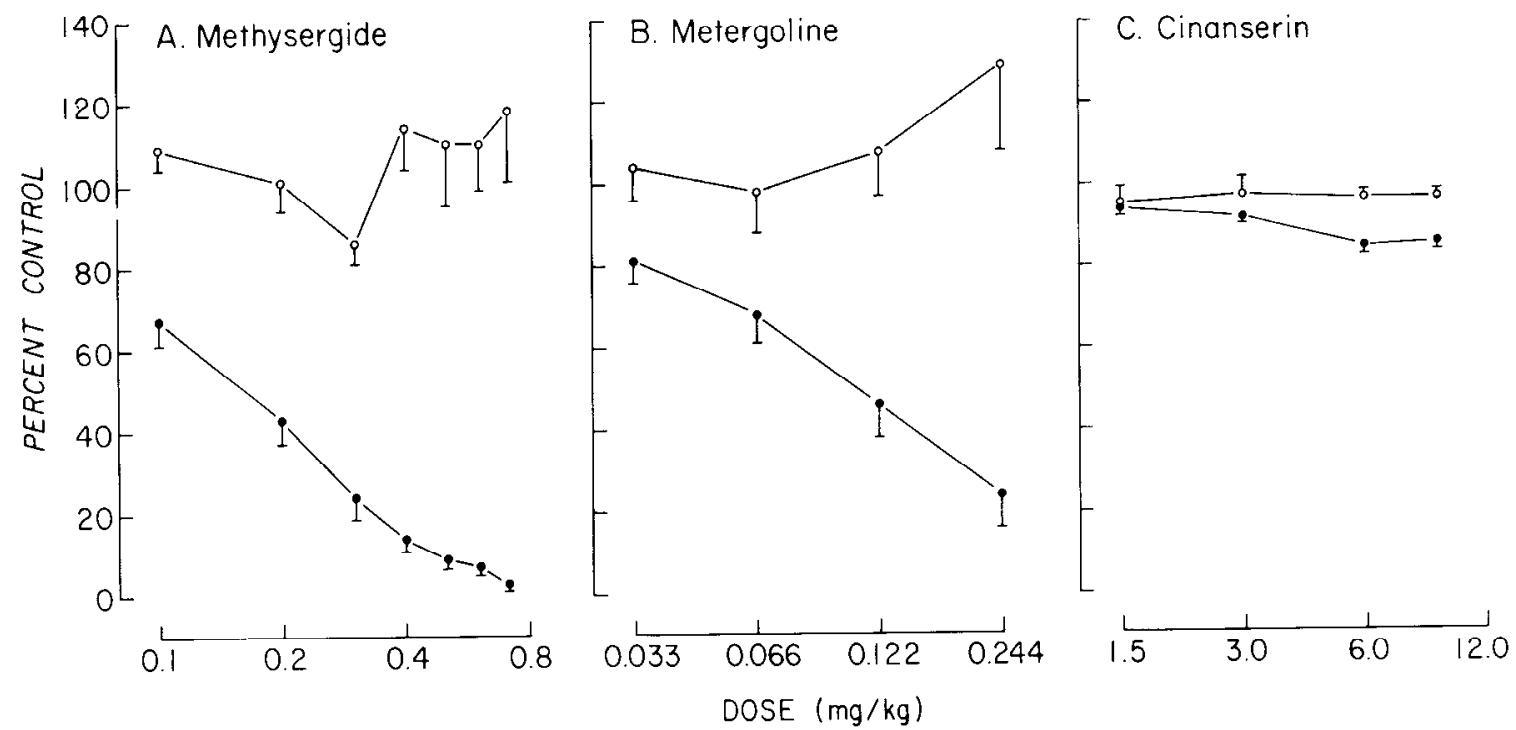

Figure 7. Cumulative dose-response curves of the effects of serotonin antagonists on averaged $\mathrm{C} 5$ phrenic nerve responses elicited by electrical stimulation of the raphe obscurus during inspiration. $A$, Methysergide; $B$, metergoline; $C$, cinanserin. Stimulus parameters: $50 \mu \mathrm{A}, 20 \mathrm{~Hz}$, and 150 $\mu \mathrm{sec}$. Early response, open circles; delayed response, filled circles. Values are means $\pm \mathrm{SEM} ; n=$ three to five cats at each point.

sulted in an increase in overall phrenic nerve activity, which is consistent with the delayed excitatory response observed in the present study. Our pharmacological data also suggest that activation of cell bodies in RO is responsible for the delayed response in the phrenic nerve. Serotonin is found primarily in cell bodies of raphe nuclei, and is thought to be a neurotransmitter used by these neurons (Dahlström and Fuxe, 1964; Poitras and Parent, 1978; Wiklund et al., 1981). Therefore, activation of cell bodies of RO would be expected to release serotonin and activate serotonin receptors. All three serotonin receptor antagonists used in this study caused inhibition of the delayed response, strongly suggesting that activation of serotonergic cell bodies of RO is responsible for at least part of the delayed response. The presence of the delayed response to stimulation lateral to midline may be due to activation of neural processes arising from RO cell bodies that enter the reticular formation (Fox et al., 1976).

Our pharmacological data indicatc that a scrotoncrgic synapsc is involved in mediating the delayed response. Methysergide, metergoline, and cinanserin are selective and competitive serotonin receptor antagonists (Leysen et al., 1982; Peroutka et al., 1981) that have been shown to block the facilitatory actions of scrotonin (McCall, 1984; McCall and Aghajanian, 1980). However, some caution must be used in drawing conclusions about actions of drugs in the CNS following their systemic administration. Drugs may have actions at several sites, which will all contribute to a net final effect. Although a serotonergic pathway is involved in the delayed response, it is difficult to determine conclusively from our data whether the delayed response is mediated by a monosynaptic projection directly onto phrenic motoneurons or by projections to other respiratory nuclei that then project to phrenic motoneurons.

Evidence that the delayed response is mediated to some extent by a direct monosynaptic serotonergic projection onto phrenic motoneurons is found in both neuroanatomical and physiological studies. The RO has been shown to send serotonergic projections via the ventral and ventrolateral funiculi to the ventral horn of the spinal cord (Basbaum and Fields, 1979; Dahlström and Fuxe, 1965; Martin et al., 1978). These projections terminate in the area of the PMN (Holtman et al., 1984a). In addition, serotonergic nerve terminals are found surrounding motoneurons in the spinal cord (Dahlström and Fuxe, 1965;
Steinbusch et al., 1978), including phrenic motoneurons (Holtman et al., 1984b). Furthermore, serotonin has been shown to facilitate motoneuron excitability in the spinal cord (Myslinski and Anderson, 1978; White and Neuman, 1980).

The delayed excitatory response may also be mediated by activation of medullary respiratory nuclei, which then project to and excite phrenic motoneurons. Again, there is both neuroanatomical and neurophysiological evidence supporting this possibility. Serotonin nerve terminals have been found in the nuclei of the tractus solitarius (Maley and Elde, 1982), which contains the dorsal respiratory group neurons, and in the area of the nucleus ambiguus (Steinbusch, 1981), which constitutes part of the ventral respiratory group. Neurons from both of these areas project to and excite phrenic motoneurons (Lipski et al., 1983; Merrill, 1974). Furthermore, serotonin has been shown to cause an increase in the firing rate of inspiratory neurons in the dorsal respiratory group (Sessle and Henry, 1985). Additional cvidencc indicating that the delaycd response is mediated through medullary respiratory nuclei comes from findings in the present study. The onset latency of $7.0 \mathrm{msec}$ for the delayed response is not ccnsistent with what would be expected of a monosynaptic serotonergic spinal cord projection. A conduction velocity of about $10 \mathrm{~m} / \mathrm{sec}$ for a raphe-spinal monosynaptic pathway is predicted by this onset latency. Serotonergic axons in the spinal cord are both unmyelinated and finely myelinated, and have been shown to have diameters averaging about $1 \mu \mathrm{m}$ (Dahlström and Fuxe, 1965; Ruda and Gobel, 1980). This predicted conduction velocity of $10 \mathrm{~m} / \mathrm{sec}$ is too fast for these smalldiameter axons of the raphe-spinal serotonergic pathway (Wessendorf et al., 1981). Although the onset latency is too short to explain a serotonergic raphe-spinal pathway, it could explain a slowly conducting serotonergic pathway via the dorsal and/or ventral respiratory group neurons, which then project by rapidly conducting medullary inspiratory axons to the PMN. The distance from RO to the dorsal or ventral respiratory groups is approximately $3.5 \mathrm{~mm}$ (Berman, 1968). The latency between these nuclei would be $3.5 \mathrm{msec}$, assuming a pathway with conduction velocity of $1 \mathrm{~m} / \mathrm{sec}$. Using this latency, we predict that the overall onset latency would be approximately $7.0 \mathrm{msec}$ for the disynaptic pathway between RO and the PMN. This is consistent with the experimentally determined onset latency of the delayed response observed in the present study. 
The delayed response may not be totally mediated by release of serotonin. This conclusion is based on two findings. First, the blockade of the delayed response by serotonin antagonists could be partially reversed by increasing current intensity. Second, cinanserin, which has been shown in other studies to be effective in antagonizing the facilitatory effects of serotonin (McCall, 1984; McCall and Aghajanian, 1980), was able to block only a small portion of the delayed excitatory response. These data suggest that other neurotransmitters may mediate a portion of the delayed response. Other putative neurotransmitters, such as substance $\mathrm{P}$, thyrotropin-releasing hormone, and met-enkephalin, have been identified in cell bodies of RO (Hökfelt et al., 1978; Hunt and Lovick, 1982; Johansson et al., 1981; Lovick and Hunt, 1983).

In conclusion, we have found in this study the presence of a serotonergic pathway, probably arising from cell bodies within $\mathrm{RO}$ and mediating an excitation of phrenic motoneurons. To the best of our knowledge, this constitutes the first demonstration of a specific respiratory motor responsc associated with a specific neurotransmitter and a brain stem nucleus.

\section{References}

Bainton, C. R., P. A. Kirkwood, and T. A. Sears (1978) On the transmission of the stimulating effects of carbon dioxide to the muscles of respiration. J. Physiol. (Lond.) 280: 249-272.

Basbaum, A. I., and H. L. Fields (1979) The origin of descending pathways in the dorsolateral funiculus of the spinal cord of the cat and rat: Further studies on the anatomy of pain modulation. J. Comp. Neurol. 187: 513-532.

Basbaum, A. I., C. H. Clanton, and H. L. Fields (1978) Three bulbospinal pathways from the rostral medulla of the cat: An autoradiographic study of pain modulating systems. J. Comp. Neurol. 178: 209-224.

Berger, A. J. (1977) Dorsal respiratory group neurons in the medulla of cat: Spinal projections, responses to lung inflation and superior laryngeal nerve stimulation. Brain Res. 135: 231-254.

Berger, A. J. (1979) Phrenic motoneurons in the cat: Subpopulations and nature of respiratory drive potentials. J. Neurophysiol. 42: 7690 .

Berger, A. J., D. B. Averill, and W. E. Cameron (1984) Morphology of inspiratory neurons located in the ventrolateral nucleus of the tractus solitarius of the cat. J. Comp. Neurol. 224: 60-70.

Berman, A. L. (1968) The Brain Stem of the Cat, U. Wisconsin P., Madison.

Berry, M. S., and V. W. Pentreath (1976) Criteria for distinguishing between monosynaptic and polysynaptic transmission. Brain Res. 105: 1-20.

Dahlström, A., and K. Fuxe (1964) Evidence for the existence of monoamine-containing neurons in the ccntral ncrvous systcm. I. Demonstration of monoamines in cell bodies of brain stem neurones. Acta Physiol. Scand. (Suppl. 232) 62: 1-55.

Dahlström, A., and K. Fuxe (1965) Evidence for the existence of monoamine neurons in the central nervous system. II. Experimentally induced changes in the intraneuronal amine levels of bulbospinal neuron systems. Acta Physiol. Scand. (Suppl. 247) 64: 1-36.

Dick, T. E., and A. J. Berger (1985) Axonal projections of single bulbospinal inspiratory neurons revealed by spike-triggered averaging and antidromic activation. J. Neurophysiol. 53: 1590-1603.

Dretchen, K. L., J. R. Holtman, Jr., B. L. Hamilton, W. P. Norman, and R.A. Gillis (1983) Effect of electrical stimulation of raphe nuclei on spontaneous phrenic nerve activity. Fed. Proc. 42: 331.

Eccles, J. C. (1968) The Physiology of Nerve Cells, Johns Hopkins P., Baltimore, MD.

Fox, G. Q., G. D. Pappas, and D. P. Purpura (1976) Morphology and fine structure of the feline neonatal medullary raphe nuclei. Brain Res. 101: 385-410.

Fuller, R. W. (1980) Pharmacology of central serotonin neurons. Annu. Rev. Pharmacol. Toxicol. 20: 111-127.

Goodchild, A. K., R. A. L. Dampney, and R. Bandler (1982) A method for evoking physiological responses by stimulation of cell bodies, but not axons of passage, within localized regions of the central nervous system. J. Neurosci. Methods 6: 351-363.

Hökfelt, T., A. Ljungdahl, H. Steinbusch, A. J. Verhofstad, G. Nilsson,
B. Brodin, B. Pernow, and M. Goldstein (1978) Immunohistochemical evidence of substance P-like immunoreactivity in some 5-hydroxytryptamine-containing neurons in the rat central nervous system. Neuroscience 3: 517-538

Holtman, J. R., Jr., W. P. Norman, and R. A. Gillis (1984a) Projections from the raphe nuclei to the phrenic motor nucleus in the cat. Neurosci. Lett. 44: 105-111.

Holtman, J. R., Jr., W. P. Norman, L. Skirboll, K. L. Dretchen, C. Cuello, T. J. Visser, T. Hökfelt, and R. A. Gillis (1984b) Evidence for 5-hydroxytryptamine, substance $P$ and thyrotropin-releasing hormone in neurons innervating the phrenic motor nucleus. J. Neurosci. 4: 1064-1071.

Holtman, J. R., Jr., N. C. Anastasi, W. P. Norman, and K. L. Dretchen (1986) Effect of electrical and chemical stimulation of the raphe obscurus on phrenic nerve activity in the cat. Brain Res. 362: 214220.

Hunt, S. P., and T. A. Lovick (1982) The distribution of serotonin, met-enkephalin and $\beta$-lipotropin-like immunoreactivity in neuronal perikarya of the cat brainstem. Neurosci. Lett. 30: 139-145.

Johansson, O., T. Hökfelt, B. Pernow, S. L. Jeffcoate, N. White, H. W. M. Steinbusch, A. A. J. Verhofstad, P. C. Emson, and E. Spindel (1981) Immunohistochemical support for three putative transmitters in one neuron: Coexistence of 5-hydroxytryptamine, substance $P$, and thyrotropin releasing hormone-like immunoreactivity in medullary neurons projecting to the spinal cord. Neuroscience 6: 1857-1881.

Lalley, P. M. (1985) Influence of caudal raphe complex on phrenic motoneurons. In Neurogenesis of Central Respiratory Rhythm, A. L. Bianchi and M. Denavit-Saubie, eds., pp. 99-102, MTP, Lancaster, UK.

Leysen, J. E., C. J. E. Niemegeers, J. M. Van Nueten, and P. M. Laduron (1982) $\left[{ }^{3} \mathrm{H}\right]$ Ketanserin $(\mathrm{R} 41468)$, a selective ${ }^{3} \mathrm{H}$-ligand for serotonin $_{2}$ receptor binding sites. Mol. Pharmacol. 21: 301-314.

Lipski, J., L. Kubin, and J. Jodkowski (1983) Synaptic action of $\mathbf{R}_{\beta}$ neurons on phrenic motoneurons studied with spike-triggered averaging. Brain Res. 288: 105-118.

Lovick, T. A., and S. P. Hunt (1983) Substance P-immunoreactive and serotonin-containing neurones in the ventral brainstem of the cat. Neurosci. Lett. 36: 223-228.

Maley, B., and R. Elde (1982) Immunohistochemical localization of putative neurotransmitters within the feline nucleus tractus solitarii. Neuroscience 7: 2469-2490.

Martin, R. F., L. M. Jordan, and W. D. Willis (1978) Differential projections of cat medullary raphe neurons demonstrated by retrograde labelling following spinal cord lesions. J. Comp. Neurol. 182: $77-88$.

McCall, R. B. (1984) Evidence for a serotonergically mediated sympathoexcitatory response to stimulation of medullary raphe nuclei. Brain Res. 311: 131-139.

McCall, R. B., and G. K. Aghajanian (1980) Pharmacological characterization of serotonin receptors in the facial motor nucleus: A microiontophoretic study. Eur. J. Pharmacol. 65: 175-183.

Mcrrill, E. G. (1974) Finding a respiratory function for the mcdullary respiratory neurons. In Essays on the Nervous System, R. Bellairs and E. G. Gray, eds., pp. 451-486, Clarendon, Oxford, UK.

Myslinski, N. R., and E. G. Anderson (1978) The effects of serotonin precursors on $\alpha$ - and $\gamma$-motoneuron activity. J. Pharmacol. Exp. Ther. 204: $19-26$

Oliveras, J. L., S. Bourgoin, F. Hery, J. M. Besson, and M. Hamon (1977) The topographical distribution of serotoninergic terminals in the spinal cord of the cat: Biochemical mapping by the combined use of microdissection and microassay procedures. Brain Res. 138: 393406.

Palkovits, M. M. Brownstein, and J. M. C. Saavedra (1974) Serotonin content of brain stem nuclei in the rat. Brain Res. 80: 237-249.

Peroutka, S. J., R. M. Lebovitz, and S. H. Snyder (1981) Two distinct central serotonin receptors with different physiological functions. Science 212: 827-829.

Pitts, R. F. (1943) The basis for repetitive activity in phrenic motoneurons. J. Neurophysiol. 6: 439-454.

Pitts, R. F., H. W. Magoun, and S. W. Ranson (1939) Localization of the medullary respiratory centers in the cat. Am. J. Physiol. 126:673688.

Poitras, D., and A. Parent (1978) Atlas of the distribution of monoamine-containing nerve cell bodies in the brain stem of the cat. $J$. Comp. Neurol. 179: 699-718.

Proudfit, H. K., and E. G. Anderson (1974) New long latency bul- 
bospinal evoked potentials blocked by serotonin antagonists. Brain Res. 65: 542-546.

Ruda, M. A., and S. Gobel (1980) Ultrastructural characterization of axonal endings in the substantia gelatinosa which take up $\left[{ }^{3} \mathrm{H}\right]$ serotonin. Brain Res. 184: 57-83.

Sessle, B. J., and J. L. Henry (1985) Effects of enkephalin and 5 -hydroxytryptamine on solitary tract neurons involved in respiration and respiratory reflexes. Brain Res. 327: 221-230.

Sessle, B. J., G. J. Ball, and G. E. Lucier (1981) Suppressive influences from periaqueductal gray and nucleus raphe magnus on respiration and related reflex activities and on solitary tract neurons, and effect of naloxone. Brain Res. 216: 145-161.

Snedecor, G. W., and W. G. Cochran (1967) Statistical Methods, Iowa State U. P., Ames, IA.

Steinbusch, H. W. M. (1981) Distribution of serotonin-immunoreactivity in the central nervous system of the rat-cell bodies and terminals. Neuroscience $6: 557-618$.
Steinbusch, H. W. M., A. A. J. Verhofstad, and H. W. J. Joosten (1978) Localization of serotonin in the central nervous system by immunohistochemistry: Description of a specific and sensitive technique and some applications. Neuroscience 3: 811-819.

Taber, E., A. Brodal, and F. Walberg (1960) The raphe nuclei of the brain stem in the cat. I. Normal topography and cytoarchitecture and general discussion. J. Comp. Neurol. 114: 161-188.

Wessendorf, M. W., H. K. Proudfit, and E. G. Anderson (1981) The identification of serotonergic neurons in the nucleus raphe magnus by conduction velocity. Brain Res. 214: 168-173.

White, S. R., and R. S. Neuman (1980) Facilitation of spinal motoneurone excitability by 5 -hydroxytryptamine and noradrenaline. Brain Res. 188: 119-127.

Wiklund, L., L. Leger, and M. Persson (1981) Monoamine cell distribution in the cat brain stem. A fluorescence histochemical study with quantification of indolaminergic and locus coeruleus cell groups. J. Comp. Neurol. 203: 613-647. 